Volume 19, No 4 International Journal of Radiation Research, October 2021

\title{
Metformin plus radiotherapy effect on diabetic patients with Non-small-cell lung carcinoma: an updated systematic review and meta-analysis
}

\author{
R. Zhao', J. Xin'1, H. Xiao ${ }^{2}$, P. Li' ${ }^{3}$, X. Zhu ${ }^{*}$ \\ ${ }^{1}$ Department of Intervention the Second Affiliated Hospital of Mudanjiang Medical College, Mudanjiang, 157000, \\ Heilongjiang, China \\ ${ }^{2}$ Department of Neurology, the Second Affiliated Hospital of Mudanjiang medical college, Mudanjiang, 157000, \\ Heilongjiang, China \\ 3 Department of Radiotherapy, Jiamusi Central Hospital, Jiamusi, 154002, Heilongjiang, China \\ ${ }^{4}$ Department of Radiology, the Second Affiliated Hospital of Mudanjiang Medical College, Mudanjiang, 157000, \\ Heilongjiang, China
}

\section{- Review article}

\section{*Corresponding authors:}

Xиуао Zhu, Ph.D.,

E-mail: prof.xia.Li@gmail.com

Revised: July 2020

Accepted: August 2020

Int. J. Radiat. Res., October 2021; 19(4): $771-778$

DOI: 10.29242/ijrr.19.4.771

\begin{abstract}
Background: Non-small-cell lung carcinoma (NSCLC) as the most common type of lung cancer has the most leading mortality rate among other cancers. Diabetes mellitus is one of the most common comorbidities of this disease. Metformin is a conventional anti-diabetic drug that is evaluated in various studies as an anti-cancer agent. This study was an updated systematic review and meta-analysis evaluating the effect of metformin on NSCLC. Materials and Methods: A systematic search was conducted through PubMed/Medline, EMBASE, and Cochrane library databases and all retrospective studies with the title the effect of metformin on the non-small cell lung cancer were collected. Statistical analyses were carried out using either random-effects or fixed-effects models according to the heterogeneity examined by $\mathrm{I}^{2}$ statistics and assessing Hazard Ratio of overall survival (OS) using Revman version 5 software. Result: Fourteen studies involving 3164 patients were included in the current meta-analysis. The pooled hazard ratio (HR) of comparison of overall survival (OS) between metformin user diabetic patients and diabetic patients without a history of using metformin was $0.87(95 \% \mathrm{Cl} 0.74-1.02$; $\mathrm{P}$ $=0.08$ ). Sub-group analysis showed that when studies were divided by region the HR of OS for Asia was 0.77 (95\% Cl 0.65-0.90; P = 0.001), $1.11(95 \% \mathrm{Cl}$ $0.72-1.71 ; P=0.64)$ for USA, and $0.86(95 \% \mathrm{Cl} 0.57-1.30 ; \mathrm{P}=0.47)$ for Europe. Conclusion: The use of metformin beside radiotherapy in patients with type 2 diabetes may be associated with a good prognosis. While this impact was just significantly seen in Asian studies.
\end{abstract}

Keywords: Metformin, diabetes mellitus, non-small cell lung carcinoma (NSCLC).

\section{INTRODUCTION}

Lung cancer in developing countries has the most leading death rate among cancers (about one-third of all cancers) and about one million people die each year due to this disease $(1,2)$. There are two main types of lung cancer are Small-cell carcinoma (SCLC) and Non-small-cell lung carcinoma (NSCLC), in which NSCLC has rated the most common type of lung cancers ${ }^{(3,4)}$. The average survival of NSCLC patients is only about 4 to 5 months (5). NSCLC patients undergo radiotherapy along with chemotherapy, although these therapies may not produce the desired therapeutic response (6). Diabetes mellitus is one of the most common comorbidities in patients with lung cancer (7). Metformin prescription as an anti-diabetic drug 
is less common than other oral diabetes drugs, while is considered as first-line treatment in type 2 diabetic patients $(8,9)$. Metformin is extracted from a French plant called lilac, (the scientific name: Galega officinalis), which was first introduced in the medical textbooks of the seventeenth century onward, as a cure for symptoms now known as diabetes (10,11). If administered followingthe guidelines, it is easily tolerated by patients because of its great efficacy in many clinical conditions and it's low toxicity (12). Since the association of metformin with cancer was first reported by Evans et al. (13), A study by Wink et al. In 682 patients with non-small cell lung cancer found that metformin use along with chemotherapy increased the survival rate of patients $\left.{ }^{14}\right)$. Xu et al., in a study of 76 patients with small cell lung cancer and type 2 diabetes, showed that metformin could be considered an anticancer drug (15).

Lin et al., conducted a study of 750 patients with stage 4 non-small cell lung cancer who also had type 2 diabetes, found that metformin has anti-cancer effects even in the late stages of cancer (16). While, In a case-control study conducted by Bodmer et al based on the General Practice Research Database (GPRD), metformin use was not associated with a reduced risk of lung cancer (18).

As there are many studies concerning the metformin prescription in diabetic patients or non-diabetics along with the routine radiotherapy and chemotherapy regimens of NSCLC treatment, and due to the controversies among those studies, this study aimed to review the impact of metformin therapy in NSCLC patients undergoing radiotherapy.

\section{MATERIALS AND METHODS}

\section{Study design}

The present systematic review and meta-analysis study was conducted based on the Systematic Studies and Meta-Analysis Reporting System (PRISMA) statement with the aim of evaluating metformin plus radiotherapy effect on a diabetic patient with Non-small-cell lung carcinoma.

\section{Search strategy}

The present study was conducted in several stages of precise determination of study, collecting, analyzing, and interpreting the findings. Published articles in English about the metformin therapy in NSCLC were collected, searching the science direct, PubMed, EMBASE, and Cochrane library databases with keywords of "Non-small-cell lung carcinoma", "Metformin', "Radiotherapy", and 'diabetic" by two independent researchers. All relevant articles published by 1990- 2020 were extracted.

\section{Inclusion criteria}

Initially, all retrospective studies with the title the effect of metformin on the non-small cell lung cancer with Type 2 diabetes mellitus were collected, and a list of abstracts were prepared. Non-relevant and duplicated studies were excluded. The full text of the relevant articles was then provided (as shown in the flow diagram in figure 1). Two researchers studied each article independently. In case of disagreement between two researchers, the third author judged the article. Articles reporting the HR of overall survival (OS) were included after the full-text review.

\section{Quality and bias assessment}

The Strengthening the Reporting of Observational Studies in Epidemiology (STROBE) checklist was used to assess study quality, which had 43 items. We included studies with a minimum score of 40 so that we did not need bias assessment as it was considered in the checklist. The criterion was set by the above protocol and after identifying the studies by our team (including supervisor group and searcher individual, consultant group, data extractor, and collector).

\section{Statistical analysis}

The variance of each study was calculated by the fixed-effect model. Then studies were combined according to random-effects models. Due to the heterogeneity in the studies, the random-effects model was used to combine the pooled HR. Cochran test and $\mathrm{I}^{2}$ index were used to evaluate the heterogeneity of the studies. For

Int. J. Radiat. Res., Vol. 19 No. 4, October 2021 
this reason, it was attempted to determine the cause of heterogeneity by subgroup analysis. Data were analyzed using Revman version 5 software (Cochrane, United Kingdom).

\section{RESULTS}

The current meta-analysis was carried out in accordance with the guidelines of PRISMA (26). In the current meta-analysis, finally, 14 studies were included. The characteristics of the studies are shown in table 1.

In the meta-analysis of pooled Overall Survival of diabetic patients receiving Metformin vs. diabetic patients without Metformin use, 14 studies with 7055 participants were included. The heterogeneity was not high $\left(\mathrm{I}^{2}=71 \%\right)$. Random fixed-effect model analysis of Hazard ratios revealed that there was not any statistically significant difference in OS $(\mathrm{P}=0.08)$.

In the meta-analysis of combined Overall Survival of diabetic patients receiving Metformin vs. diabetic patients without Metformin use in the continents, According to the figure 3, there was a significant effect of metformin in the continent of Asia among diabetics who used metformin vs. those with diabetes who did not use metformin $(p=0.001)$. However, there were no significant differences in the two continents of America and Europe $(\mathrm{P}>0.005)$.

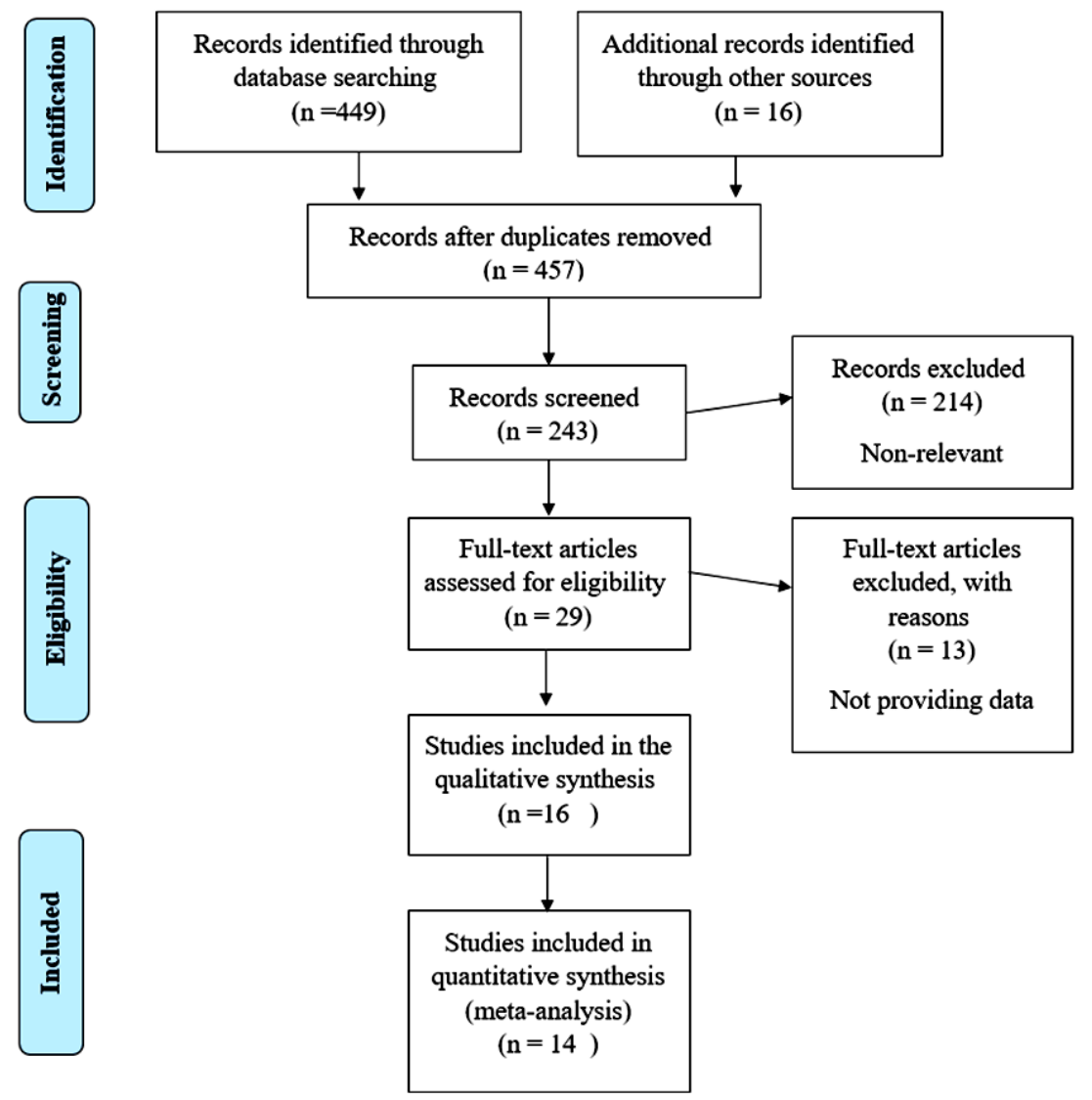

Figure 1. Flow chart showing the process of study selection. 
Table 1. The baseline characteristics of each study.

\begin{tabular}{|c|c|c|c|c|c|c|c|c|}
\hline Author & Country & years & $\mathbf{N}$ & Mean age & Female & Male & Smoking history & Reference \\
\hline Muhammad Z Afzal & USA & 2019 & 21 & 70.1 & 9 & 12 & 19 & $(27)$ \\
\hline Chuang & Taiwanese & 2018 & 2,091 & 71.2 & 830 & 1,261 & NA & $(28)$ \\
\hline Medairos RA & USA & 2016 & 81 & 69 & 39 & 42 & 66 & $(29)$ \\
\hline Ahmed I & USA & 2015 & 166 & 68.5 & 75 & 91 & 151 & $(30)$ \\
\hline Wink KC & Netherlands & 2016 & 59 & 69 & 19 & 40 & NA & $(31)$ \\
\hline Lin J & USA & 2017 & 259 & NA & 78 & 181 & NA & $(32)$ \\
\hline Wen-Xiu X & China & 2018 & 27 & NA & 21 & 6 & 19 & $(33)$ \\
\hline Tan BX & China & 2011 & 39 & 62 & 8 & 31 & NA & $(34)$ \\
\hline Dhillon & USA & 2014 & 409 & 68.5 & 237 & 172 & 37 & $(35)$ \\
\hline Xu T & China & 2015 & 79 & NA & 12 & 67 & 73 & $(36)$ \\
\hline Mazzone & USA & 2012 & 507 & NA & NA & NA & NA & $(37)$ \\
\hline Kong F & China & 2015 & 259 & 72,4 & 215 & 44 & 246 & $(38)$ \\
\hline Lin JJ & China & 2015 & 777 & 64.1 & 380 & 397 & NA & $(39)$ \\
\hline Chen H, & China & 2015 & 90 & NA & 53 & 37 & 36 & $(40)$ \\
\hline
\end{tabular}

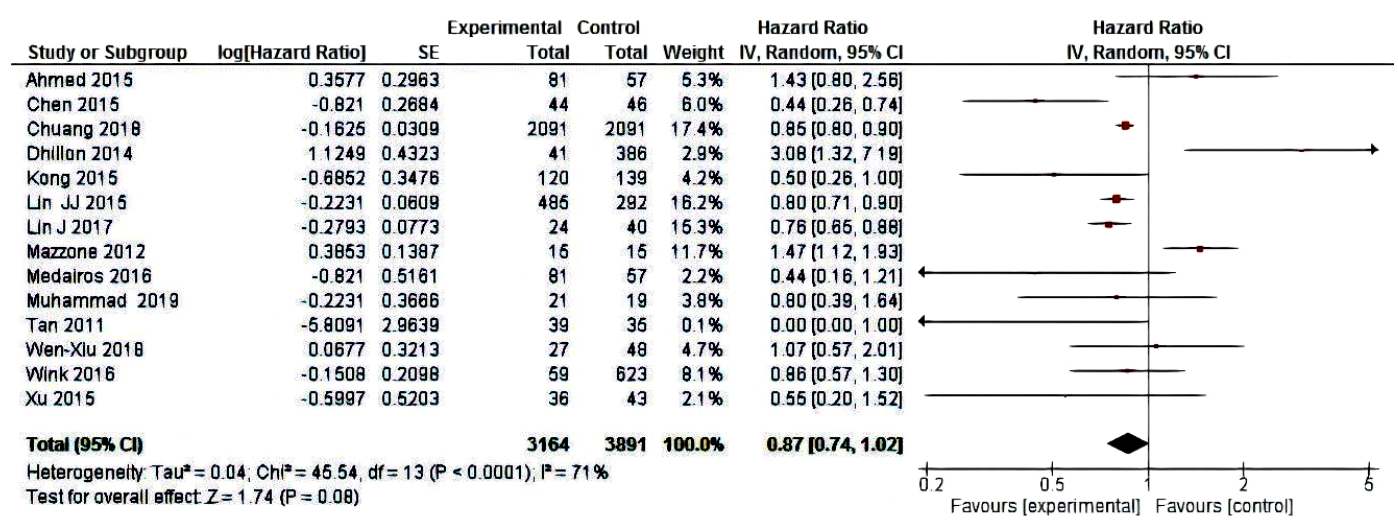

Figure 2. A meta-analysis of all the eligible studies for the hazard ratio with $95 \% \mathrm{Cl}$ of overall survival.

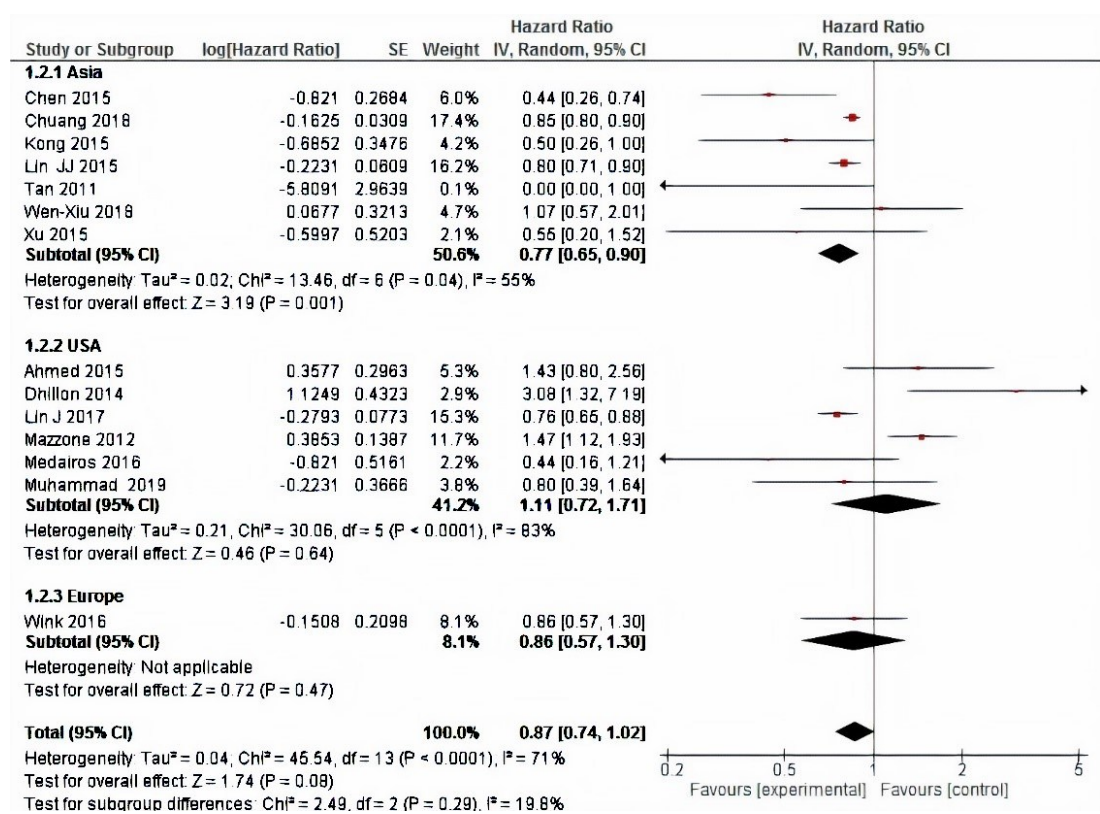

Figure 3. Sub-group analysis according to the study region (Asian, Europe, and the USA) on evaluating hazard ratio with $95 \% \mathrm{Cl}$ of overall survival. 


\section{DISCUSSION}

At the clinic, NSCLC patients receive radiotherapy and chemotherapy; however, it does not provide the desired therapeutic response in all cases. This study is a simple overview of the effect of metformin with NSCLC to help determine whether metformin can be used as adjunctive therapy with radiotherapy. Patients with lung cancer, despite radiotherapy and chemotherapy, do not survive a long time. Also, clinical results indicate that the side effects of radiotherapy treatment are largely dependent on the amount of absorption dose and the volume of the organ exposed to radiation, today. Therefore, a lot of attention has been paid to adjacent treatment regimens to eliminate cancerous tumors and improve the outcome of treatment. Metformin is one of these candidates that may be used as an adjunct to radiotherapy and chemotherapy.

Many recent studies have focused on the anticancer effect of metformin in NSCLC as a potential adjuvant therapy with radiotherapy. Our meta-analysis evaluated the effect of metformin on the overall survival of patients with type 2 diabetes mellitus and NSCLC. We assessed 14 articles to perform this meta-analysis. The results of the data analysis showed that metformin did not improve the overall survival of patients with type 2 diabetes in America and Europe. However, in Asia, there was a significant improvement of OS in patients with NSCLC using metformin. This shows shreds of evidence of different approaches or different responses to metformin medication in various countries.

It seems important to evaluate the anticancer effect of metformin as a cheap and available drug for people with lung cancer who also have diabetes. However, some inconsistencies are seen in the results obtained in previous studies. In the study of Tan et al. in china, by examining the records of 5 hospitalized patients with non-small cell lung cancer and type 2 diabetes who were undergoing first-line chemotherapy, found that metformin significantly increased chemotherapy efficacy (17). In a study by Mazzone et al. in the USA, Using electronic medical records from Cleveland Clinic, it was found that the use of metformin or thiazolidinediones was associated with a reduced risk of lung cancer in diabetic patients and increasing their response to the radiation therapy (20).

Tsai et al., in a cohort study using data from one million Taiwanese patients with lung cancer and diabetes mellitus, concluded that metformin use in diabetic patients reduced the risk of lung cancer in a dose-dependent manner (21). In a study by Sayed et al. on patients with stage 4 non -small cell lung cancer who also had type 2 diabetes showed that the combined use of Gemcitabine/ Cisplatin and metformin reduced the incidence of chemotherapy-induced nausea (22). In a study of 8263 diabetic patients, Kow and colleagues claimed that metformin had no effect on cancer incidence in diabetics patients (23).

In addition, the anti-cancer effect of metformin has been evaluated in other types of cancer. A study by Van De Voordes et al. on 196 esophageal cancer patients with diabetes found that metformin is associated with improved survival from distant metastasis (19). Recently, extensive studies have been conducted on the association of metformin with cancer-related mortality $(14,17,22,41)$. So far, some studies have indicated a 30 percent reduction in cancer risk in diabetic patients (20). The drug's ability to treat breast cancer has previously been evaluated (42). $\mathrm{Wu}$ et al. then showed for the first time that metformin inhibited the growth of lung cancer cells and induced cancer cell apoptosis (25).

However, some studies have shown little association between metformin use and the severity of cancer progression. In some studies, the reduced risk of lung cancer associated with diabetes mellitus has been reported, while much research has rejected this hypothesis (18). Memmott et al. have been conducted a study of J/A mice on the association of metformin and prevention of tobacco-induced lung tumor genesis through inhibition of mTOR pathways $(44,45)$.

The precise molecular mechanism of the anticancer effect of metformin has not been elucidated to date, but its possible mechanisms are as following: First, metformin crosses the 
cancer cell membrane as an mTOR inhibitor by activating the AMPK pathway and inhibiting cascade signaling $(45,35,30)$.

mTOR is a molecule that plays an important role in the anti-cancer effects of metformin (47). Metformin may act to treat many cancers that these signaling pathways of specific tumorigenic mutations are responsible (29).

Secondly, it reduces circulating insulin levels by increasing cell sensitivity to insulin; this eliminates the growth factor that will induce insulin receptor expression in the tumor cell. These actions lead to increased levels of autophagy, apoptosis, cell cycle arrest, and reduced levels of protein synthesis, cell proliferation, migration, and invasion (16). In addition, other mechanisms have been briefly attributed to metformin.

A study has shown that metformin inhibits lung cancer by suppressing MicroRNA222 (48). Suppression of MicroRNA222 results in increased levels of p27, p57, and PTEN molecules, and increased levels of these molecules disrupt the cell cycle in tumor cells, and its effect in decreasing the radioresistance was indicated in this study (49). Of course, since this study was performed in vitro, it cannot be predicted the accuracy of this mechanism in biological systems. In addition, metformin induces immune activation and apoptosis and reduces growth factor signaling (46). In this way, it prevents the mitosis of cancer cells. Metformin can also inhibit solid tumors by increasing the number of CD8+ TIL lymphocytes and protecting them from apoptosis (36). It is worth noting that the anticancer effect of metformin is probably dose-dependent (30).

Based on immunohistochemical and PCR studies, the anticancer effects of metformin with gene regulation (MMP-2) (Matrix Metalloproteinase-2) have been demonstrated (30). However, overexpression of 2MMP is associated with the incidence of cancers such as NSCLC (50).

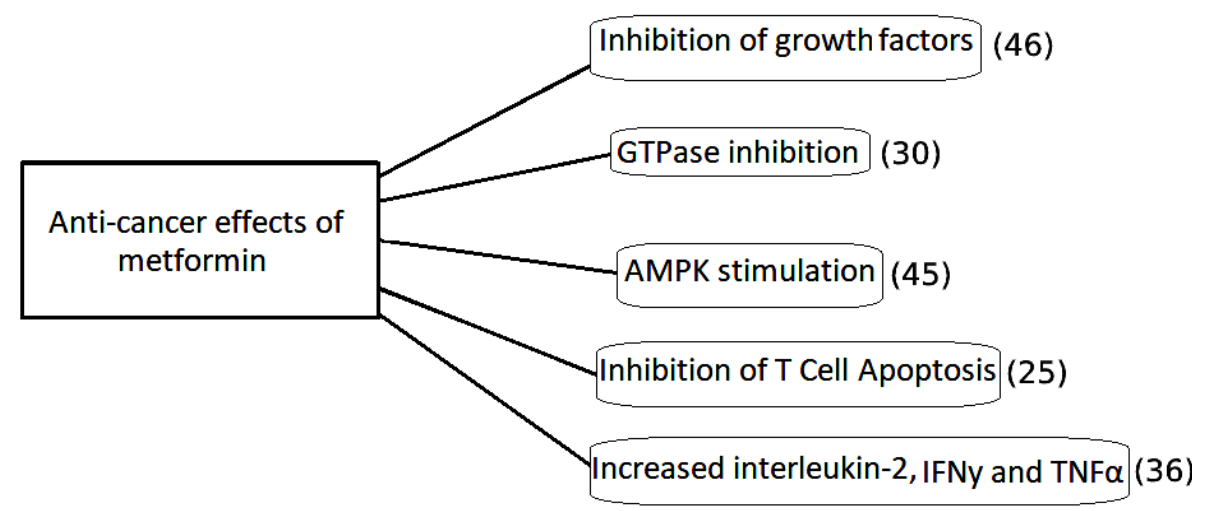

Figure 4. Possible mechanisms of metformin against antitumor effects.

Some recent studies have reported this drug as an anti-diabetic agent, with reports of increased homocysteine levels and a decrease in folate and vitamin B12 in patients with type 2 diabetes mellitus after long-term use of metformin (51,52). In-vitro and in-vivo studies have shown that metformin inhibits the proliferation of cancer cells (53).

One of the limitations of this study is the fact that we couldn't collect studies reporting metformin as an adjuvant of radiotherapy in non -diabetic patients. All studies performed in this era are retrospective studies assessing diabetic 776 patients' response to metformin treatment along with the radiotherapy. While interventional studies are not conducted to assess metformin effect on the radiotherapy outcome instead of its antihyperglycemic effects.

\section{CONCLUSION}

Metformin with several different mechanisms may lead to reduced risk or increased recovery of non-small cell lung cancer. However, the results have been somewhat contradictory Int. J. Radiat. Res., Vol. 19 No. 4, October 2021 
mostly due to differences in races. Metformin may be used at bedside as an adjunct to radiotherapy and chemotherapy. It is suggested in future studies to investigate the anticancer use of metformin in non-diabetic patients with NSCLC.

\section{Conflicts of interest: Declared none.}

\section{REFERENCES}

1. Torre LA, Bray F, Siegel RL, Ferlay J, Lortet-Tieulent J, Jemal A (2015) Global cancer statistics, 2012. CA Cancer J Clin, 65(2): 87-108.

2. Kalemkerian GP, Akerley W, Bogner P, Borghaei $\mathrm{H}$, Chow LQ, Downey RJ, et al. (2013) Small cell lung cancer. J Natl Compr Cancer Netw, 11(1): 78-98.

3. Chen YQ, Chen G (2015) Combined therapeutic effect and molecular mechanisms of metformin and cisplatin in human lung cancer xenografts in nude mice. $J$ Cancer Res Ther, 11(2): 324-30.

4. Molina JR, Yang P, Cassivi SD, Schild SE, Adjei AA (2008) Non-small cell lung cancer: Epidemiology, risk factors, treatment, and survivorship. Mayo Clin Proc, 83(5): 58494.

5. Rapp E, Pater JL, Willan A, Cormier Y, Murray N, Evans WK, et al. (1988) Chemotherapy can prolong survival in patients with advanced non-small-cell lung cancer-report of a Canadian multicenter randomized trial. J Clin Oncol, 6 (4): 633-41.

6. Wang J, Xia S, Zhu Z (2015) Synergistic effect of phenformin in non-small cell lung cancer (NSCLC) ionizing radiation treatment. Cell Biochem Biophys, 71(2): 513-8.

7. Yendamuri S (2014) Metformin and lung cancer. J Clin Sci Res, 3: 26-32.

8. Hariharan M, Rajan S, Srinivasan R (1989) Structure of metformin hydrochloride. Acta Crystallogr C, 45(6): 911-3.

9. Zhang ZJ, Bi Y, Li S, Zhang Q, Zhao G, Guo Y, et al. (2014) Reduced risk of lung cancer with metformin therapy in diabetic patients: A systematic review and meta-analysis. Am J Epidemiol, 180(1): 11-4.

10. Lei Y, Yi Y, Liu Y, Liu X, Keller ET, Qian CN, et al. (2017) Metformin targets multiple signaling pathways in cancer. Chin J Cancer, 36(1): 17.

11. Bailey CJ and Day C (1989) Traditional plant medicines as treatments for diabetes. Diabetes Care, 12(8): 553-64.

12. Thomas I and Gregg B (2017) Metformin; a review of its history and future: From lilac to longevity. Pediatr Diabetes, 18(1): 10-6.

13. Evans JM, Donnelly LA, Emslie-Smith AM, Alessi DR, Morris AD (2005) Metformin and reduced risk of cancer in diabetic patients. BMJ, 330(7503): 1304-5.

14. Wink KC, Belderbos JS, Dieleman EM, Rossi M, Rasch CR, Damhuis RA, et al. (2016) Improved progression-free sur-

Int. J. Radiat. Res., Vol. 19 No. 4, October 2021 vival for patients with diabetes and locally advanced nonsmall cell lung cancer (NSCLC) using metformin during concurrent chemoradiotherapy. Radiother Oncol, 118(3): 453-9.

15. Xu T, Liang G, Yang L, Zhang F (2015) Prognosis of small cell lung cancer patients with diabetes treated with metformin. Clin Transl Oncol, 17(10): 819-24.

16. Lin JJ, Gallagher EJ, Sigel K, Mhango G, Galsky MD, Smith $C B$, et al. (2015) Survival of patients with stage IV lung cancer with diabetes treated with metformin. Am J Respir Crit Care Med, 191(4): 448-54.

17. Tan BX, Yao WX, Ge J, Peng XC, Du XB, Zhang R, et al. (2011) Prognostic influence of metformin as first-line chemotherapy for advanced nonsmall cell lung cancer in patients with type 2 diabetes. Cancer, 117(22): 5103-11.

18. Bodmer M, Becker C, Jick SS, Meier CR (2012) Metformin does not alter the risk of lung cancer: a case-control analysis. Lung Cancer, 78(2): 133-7.

19. Van De Voorde L, Janssen L, Larue R, Houben R, Buijsen J, Sosef M, et al. (2015) Can metformin improve "the tomorrow" of patients treated for oesophageal cancer? Eur J Surg Oncol, 41(10): 1333-9.

20. Mazzone PJ, Rai H, Beukemann M, Xu M, Jain A, Sasidhar $M$ (2012) The effect of metformin and thiazolidinedione use on lung cancer in diabetics. BMC Cancer, 12: 410.

21. Tsai MJ, Yang CJ, Kung YT, Sheu CC, Shen YT, Chang PY, et al. (2014) Metformin decreases lung cancer risk in diabetic patients in a dose-dependent manner. Lung Cancer, 86(2): 137-43.

22. Sayed R, Saad AS, El Wakeel L, Elkholy E, Badary O (2015) Metformin addition to chemotherapy in stage IV nonsmall cell lung cancer: An open label randomized controlled study. Asian Pac J Cancer Prev, 16(15): 6621-6.

23. Kowall B, Stang A, Rathmann W, Kostev K (2015) No reduced risk of overall, colorectal, lung, breast, and prostate cancer with metformin therapy in diabetic patients: database analyses from Germany and the UK. Pharmacoepidemiol Drug Saf, 24(8): 865-74.

24. Jemal A, Siegel R, Ward E, Murray T, Xu J, Thun MJ (2007) Cancer statistics, 2007. CA Cancer J Clin, 57(1): 43-66.

25. Wu N, Gu C, Gu H, Hu H, Han Y, Li Q (2011) Metformin induces apoptosis of lung cancer cells through activating JNK/ p38 MAPK pathway and GADD153. Neoplasma, 58 (6): 482-90.

26. Moher D, Liberati A, Tetzlaff J, Altman DG (2009) Preferred reporting items for systematic reviews and meta-analyses: the PRISMA statement. J Clin Epidemiol, 62: 1006-12.

27. Afzal MZ, Dragnev K, Sarwar T, Shirai K (2019) Clinical outcomes in non-small-cell lung cancer patients receiving concurrent metformin and immune checkpoint inhibitors. Lung cancer manage, 8(2): LMT11.

28. Chuang MC, Yang YH, Tsai YH, Hsieh MJ, Lin YC, Lin CK, Chen PC, Yang TM (2018) Survival benefit associated with metformin use in inoperable non-small cell lung cancer patients with diabetes: A population-based retrospective cohort study. PloS one, 13(1).

29. Medairos RA, Clark J, Holoubek S, Kubasiak JC, Pithadia R, Hamid F, Chmielewski GW, Warren WH, Basu S, Borgia JA, 


\section{Zhao et al. / Metformin plus radiotherapy effect on diabetic patients}

Liptay MJ (2016) Metformin exposure is associated with improved progression-free survival in diabetic patients after resection for early-stage non -small cell lung cancer. $J$ Thorac Cardiovasc Surg, 152(1): 55-61.

30. Ahmed I, Ferro A, Cohler A, Langenfeld J, Surakanti SG, Aisner J, Zou W, Haffty BG, Jabbour SK (2015) Impact of metformin use on survival in locally-advanced, inoperable non-small cell lung cancer treated with definitive chemoradiation. J thoracic Dis, 7(3): 346-355.

31. Wink KC, Belderbos JS, Dieleman EM, Rossi M, Rasch CR, Damhuis RA, Houben RM, Troost EG (2016) Improved progression free survival for patients with diabetes and locally advanced non-small cell lung cancer (NSCLC) using metformin during concurrent chemoradiother. Radiother Oncol, 118(3): 453-459.

32. Lin J, Gill A, Zahm SH, Carter CA, Shriver CD, Nations JA, Anderson WF, McGlynn KA, Zhu K (2017) Metformin use and survival after non-small cell lung cancer: $A$ cohort study in the US Military health system. Inter J of Cancer, 141(2): 25.

33. Wen-Xiu X, Xiao-Wei Z, Hai-Ying D, Ying-Hui T, Si-Si K, XiaoFang Z, Huang P (2018) Impact of metformin use on survival outcomes in non-small cell lung cancer treated with platinum. Med, 97(51).

34. Tan BX, Yao WX, Ge J, Peng XC, Du XB, Zhang R, Yao B, Xie K, Li LH, Dong H, Gao F (2011) Prognostic influence of metformin as first-line chemotherapy for advanced nonsmall cell lung cancer in patients with type 2 diabetes. Cancer, 117(22): 5103-11.

35. Dhillon SS, Groman A, Meagher A, Demmy T, Warren GW, Yendamuri S (2014) Metformin and not diabetes influences the survival of resected early stage NSCLC patients. $J$ of Cancer Science \& Therapy, 6(7): 217.

36. Xu T, Liang G, Yang L, Zhang F (2015) Prognosis of small cell lung cancer patients with diabetes treated with metformin. Clin and Trans Onco, 17(10): 819-24.

37. Mazzone PJ, Rai H, Beukemann M, Xu M, Jain A, Sasidhar $M$ (2012) The effect of metformin and thiazolidinedione use on lung cancer in diabetics. Bmc Cancer, 12(1): 410.

38. Kong F, Gao F, Liu H, Chen L, Zheng R, Yu J, Li X, Liu G, Jia Y (2015) Metformin use improves the survival of diabetic combined small-cell lung cancer patients. Tumor Biology, 36(10): 8101-6.

39. Lin JJ, Gallagher EJ, Sigel K, Mhango G, Galsky MD, Smith CB, LeRoith D, Wisnivesky JP (2015) Survival of patients with stage IV lung cancer with diabetes treated with metformin. US J of Res and Critic Care Med, 191(4): 448.

40. Chen H, Yao W, Chu Q, Han R, Wang Y, Sun J, Wang D, Wang Y, Cao M, He Y (2015) Synergistic effects of metformin in combination with EGFR-TKI in the treatment of patients with advanced non-small cell lung cancer and type 2 diabetes. Cancer Letters, 369(1): 97-102.

41. Van De Voorde L, Janssen L, Larue R, Houben R, Buijsen J, Sosef $M$, et al. (2015) Can metformin improve "the tomorrow" of patients treated for oesophageal cancer? Eur J Surg Oncol, 41(10): 1333-9.

42. Gonzalez-Angulo AM and Meric-Bernstam F (2010) Metformin: A therapeutic opportunity in breast cancer. Clin Cancer Res, 16(6): 1695-700.

43. Maynard GD (1910) A statistical study in cancer deathrates. Biometrika, 7(3): 276-304.

44. Antonoff MB and D'Cunha J (2010) Teaching an old drug new tricks: Metformin as a targeted therapy for lung cancer. Semin Thorac Cardiovasc Surg, 22(3): 195-6.

45. Memmott RM, Mercado JR, Maier CR, Kawabata S, Fox SD, Dennis PA (2010) Metformin prevents tobacco carcinogeninduced lung tumorigenesis. Cancer Prev Res, 3(9): 106676.

46. Zhu N, Zhang Y, Gong YI, He J, Chen X ( 2015) Metformin and lung cancer risk of patients with type 2 diabetes mellitus: A meta-analysis. Biomed Rep, 3(2): 235-41.

47. Mackay HJ, Eisenhauer EA, Kamel-Reid S, Tsao M, Clarke B, Karakasis K, et al. (2014)Molecular determinants of outcome with mammalian target of rapamycin inhibition in endometrial cancer. Cancer, 120(4): 603-10.

48. Wang Y, Dai W, Chu X, Yang B, Zhao M, Sun Y (2013) Metformin inhibits lung cancer cells proliferation through repressing microRNA-222. Biotechnol Lett, 35(12): 2013-9.

49. Chun-Zhi Z, Lei H, An-Ling Z, Yan-Chao F, Xiao Y, Guang-Xiu $W$, et al. (2010) MicroRNA-221 and microRNA-222 regulate gastric carcinoma cell proliferation and radioresistance by targeting PTEN. BMC Cancer, 10: 367.

50. Rollin J, Regina S, Vourc'h P, lochmann S, Blechet C, Reverdiau $P$, et al. (2007) Influence of MMP-2 and MMP-9 promoter polymorphisms on gene expression and clinical outcome of non-small cell lung cancer. Lung Cancer, 56(2): 273-80.

51. Ko SH, Ko SH, Ahn YB, Song KH, Han KD, Park YM, et al. (2014) Association of vitamin B12 deficiency and metformin use in patients with type 2 diabetes. $J$ Korean Med Sci, 29(7): 965-72.

52. Aarsand AK and Carlsen SM (1998) Folate administration reduces circulating homocysteine levels in NIDDM patients on long-term metformin treatment. J Intern Med, 244(2): 169-74.

53. Martin-Castillo B, Vazquez-Martin A, Oliveras-Ferraros C, Menendez JA (2010) Metformin and cancer: Doses, mechanisms and the dandelion and hormetic phenomena. Cell Cycle, 9(6): 1057-64. 